\title{
Real size experiments of a car crash against a building column
}

\author{
B. Ferrer ${ }^{1}$, S. Ivorra ${ }^{1}$, R. Irles ${ }^{1} \&$ D. Mas $^{2}$ \\ ${ }^{I}$ Departamento de ingeniería de la Construcción, \\ Universidad de Alicante, Spain \\ ${ }^{2}$ Instituto Universitario de Física Aplicada a las Ciencias y a las \\ Tecnologias, Universidad de Alicante, Spain
}

\begin{abstract}
Several real size car crash experiments have been carried out. In these experiments low velocity impact against a building column has been tested. The experiments have been carried out on a reinforced concrete column with a rectangular section. The test was developed in an external area; therefore, both the compression load and the boundary conditions in the column had to be applied with a special device. However, the use of a real car forced one to adopt some design conditions in this device. Furthermore, to avoid the need of a driver in the car, an inclined plane and a mechanical guiding system was used.

In this paper the device, procedures and instrumentation used in these experiments are described. Five experiments were done with this system and their results are presented here.
\end{abstract}

Keywords: real size, car crash, experiment, low velocity, impact, concrete column.

\section{Motivation}

The accidental actions due to the horizontal impact of a car against a building have been included in the most recent building codes, such as EUROCODE 1 [1-3], "Minimum design loads for building and other structures" [4], the "International Building Code" [5] or "DIN 1055-9: Actions on structures. Accidental actions" [6]. All of these codes use an equivalent static load (ESL) to represent the effects of an impact. 
However, the indications given in these codes are not consistent, even between different parts of the same code. This can be checked concerning vehicle barriers and studying a particular case, i.e. according to Annex B of part 1.1 of EUROCODE 1 [1], an impact with a vehicle mass of $3000 \mathrm{~kg}$ and an initial velocity of $20 \mathrm{~km} / \mathrm{h}$ provides an ESL of $308 \mathrm{kN}$, but according to "Minimum design loads for building and other structures" [4], the ESL is 26.7 $\mathrm{kN}$.

These discrepancies are also evident for building structures. For these structures and the same impact considered before, the ESL is $166 \mathrm{kN}$ according to Annex C of Part 1.7 and Annex A of Part 2.7, both from EUROCODE 1 [2, 3], but $50 \mathrm{kN}$ according to Part 1.7 of the same EUROCODE 1 [2]. Therefore, the dispersion between the codes is noticeable. A deeper analysis of the related codes and its dispersion can be found in [7].

The horizontal impact against a building structure can happen in a car park inside of the building or the impact can come from a car driving along a street outside of the building. In the first case, the configuration of the car park is related with the value of the velocity in the moment of the impact. For car parks with long straight ways, the car can reach a velocity of $20 \mathrm{~km} / \mathrm{h}$ or even higher, not perceiving the driver a potential risk. In the second case, with a building, in an urban area, the velocity of the car can be around $50 \mathrm{~km} / \mathrm{h}$. Fortunately, the usual driver reaction before a crash is to brake, and the actual speed at impact is much lower than the circulation speed. Therefore, in the study of the impacts consequences caused by vehicles on structures, it is worth to analyze the lowspeed impacts, i.e. below $30 \mathrm{~km} / \mathrm{h}$.

Experiments typically found in the bibliography concern to high velocity crashes [8] or impacts with rigid projectile [9, 10]. In this sense, one must take into account that, during the impact, the dissipated energy by the projectile significantly affects the load transmitted to the structure. Then, the use of real cars instead of rigid projectile is essential in the study of the load transmitted to the structure and consequently in its behaviour during and after the impact.

In order to understand the crash process and to analyze its effects on the structure, a series of crash experiments have been performed with real size cars and columns. For these experiments, a column of a park car located under a street was selected. The column was compressed to simulate the load of the structure above, this load being estimated in $70 \mathrm{t}$. All the experiments were done with an impact speed of $20 \mathrm{~km} / \mathrm{h}$. During the impact, the acceleration, displacement and strain of several points in the column were registered and analyzed.

\section{Experimental setup}

\subsection{Test frame}

To apply the needed compression in the column, the frame shown in figure 1 was built. It consists on a foundation made with reinforced concrete that has 4 steel anchors and a steel upper part (figure 2). The compression in the column was 


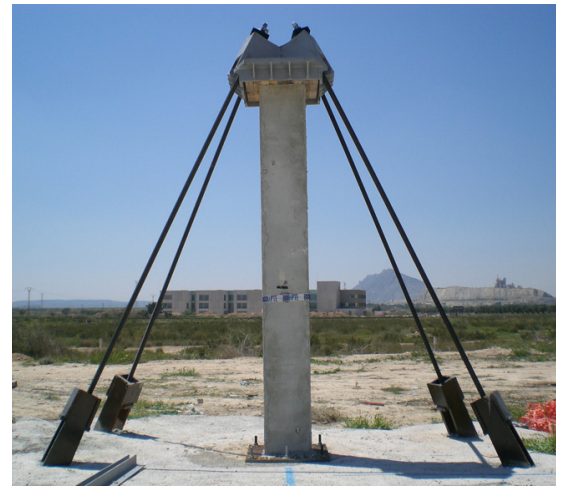

Figure 1: $\quad$ Test frame.

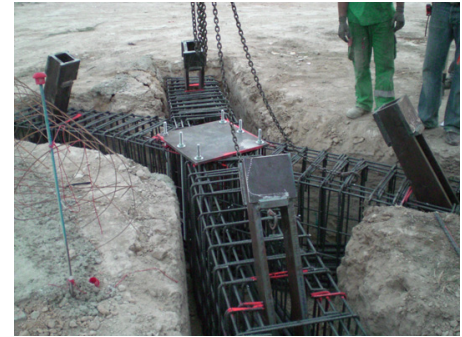

(a)

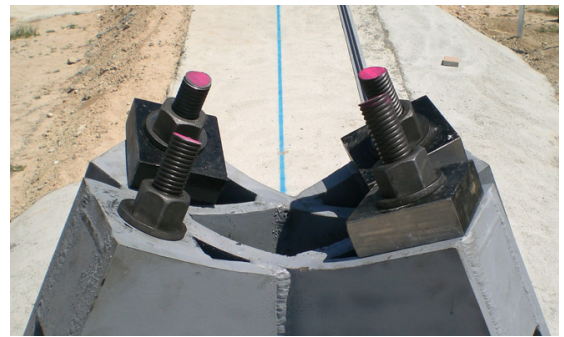

(b)

Figure 2: $\quad$ Foundation with four anchors during its construction (a) and upper part of the test frame (b).

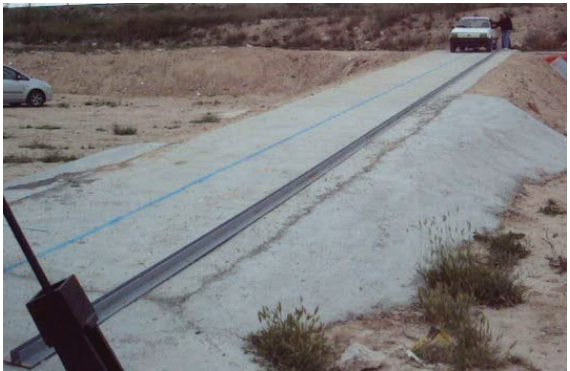

(a)

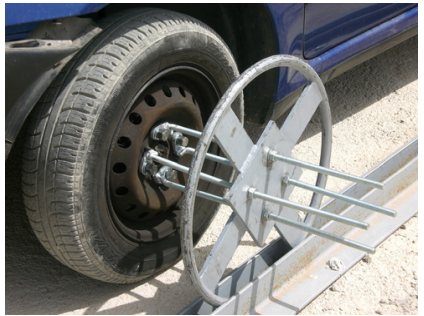

(b)

Figure 3: Ramp with metallic guide (a) and metallic wheel to maintain the direction of the car (b). 
applied by 4 bar fixed to the 4 anchors and the upper part. The anchors in the foundation were set far from the bottom of the column, to allow the car to crash against the column. An anchor plate was placed in the middle of the foundation to allow the change of the column with a simple procedure.

To provide the needed crash velocity in the cars without driver, a ramp was built. The slope and length of ramp was calculated to give a final velocity of 20 $\mathrm{km} / \mathrm{h}$ starting from 0 at the top of the ramp. The ramp is $30 \mathrm{~m}$ long and has a slope of $8.3 \%$. The fact that no driver is controlling the vehicle makes necessary to design a specific rail to maintain the direction. In figure 3(b) one can see how a metallic wheel is attached to the car in order to maintain it in the centre of the ramp (fig. 3).

\subsection{Vehicles}

Five different cars were used in the experiments. Their main characteristics are shown in table 1 . The cars came from a junkyard but still operational. This feature was necessary to properly position the vehicle on the ramp.

\subsection{Column}

The column used in all the experiments was made with reinforced concrete. This column is 2.75 high and it has rectangular section of $25 \times 35 \mathrm{~cm}$. The concrete was a $25 \mathrm{MPa}$ one and the reinforcement is shown in figure 4. In the bottom part, an anchor plate was placed to allow an easy replacement of the column in case of damage.

Once placed in its position, a compressive load of $70 \mathrm{t}$ was applied in the column by means of the test frame. To do that, a tensile load of $19.62 \mathrm{t}$ was applied to each bar of the test frame.

Table 1: $\quad$ Main characteristics of cars used in the experiment.

\begin{tabular}{cccc}
\hline Test & Vehicle & Year & Mass $(\mathrm{kg})$ \\
\hline 1 & Seat Ibiza & 1979 & 800 \\
\hline 2 & Renault 19 Chamade & 1994 & 1085 \\
\hline 3 & Seat Málaga & 1989 & 975 \\
\hline 4 & Ford Escort & 1989 & 977 \\
\hline 5 & Fiat Punto & 1994 & 830 \\
\hline
\end{tabular}

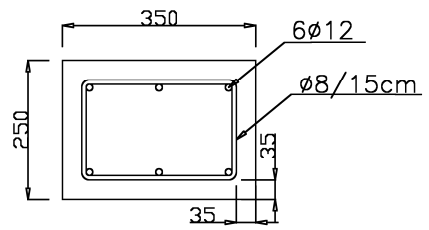

Figure 4: Column section: size ( $\mathrm{mm})$ and reinforcement. 


\subsection{Instrumentation}

Acceleration, displacement and strain in the column were registered. Before the first experiments were done, the expected acceleration peak to register was unknown. For this reason four different kinds of accelerometers were used with different measurement range: shock (350B03), triaxial (356A16), structural (333B50), seismic (393A03), all from PCB Piezotronics. The measurement range of these accelerometers is $\pm 10000 \mathrm{~g}, \pm 50 \mathrm{~g}, \pm 5 \mathrm{~g}$ and $\pm 5 \mathrm{~g}$, respectively; and the frequency range is from 0.4 to $10000 \mathrm{~Hz}, 0.5$ to $5000 \mathrm{~Hz}, 0.5$ to $3000 \mathrm{~Hz}$ and 0.5 to $2000 \mathrm{~Hz}$, respectively. After the first experiment, the registered acceleration was lower than $5 \mathrm{~g}$ in all the accelerometers, so shock accelerometers were discarded.

To register the displacement, two different systems were used. A linear displacement sensor (LDS) based on potentiometer transducer (SLS 130 Penny+Giles) with a $150 \mathrm{~mm}$ stroke length was attached to an external structure. The frequency range of the LDS is from 0 to $2000 \mathrm{~Hz}$. Additionally, a high speed camera (HSC) with 1000 frames per second and spatial resolution of 800x560 pixels was placed $2 \mathrm{~m}$ far from the column. Through this high speed camera, the movement of a target placed in the surface of the concrete was registered by means of a new image processing technique specially developed for these experiments [11]. With the camera, the measurement from linear displacement sensor can be checked to be sure that the external structure did not move at all during the impact.

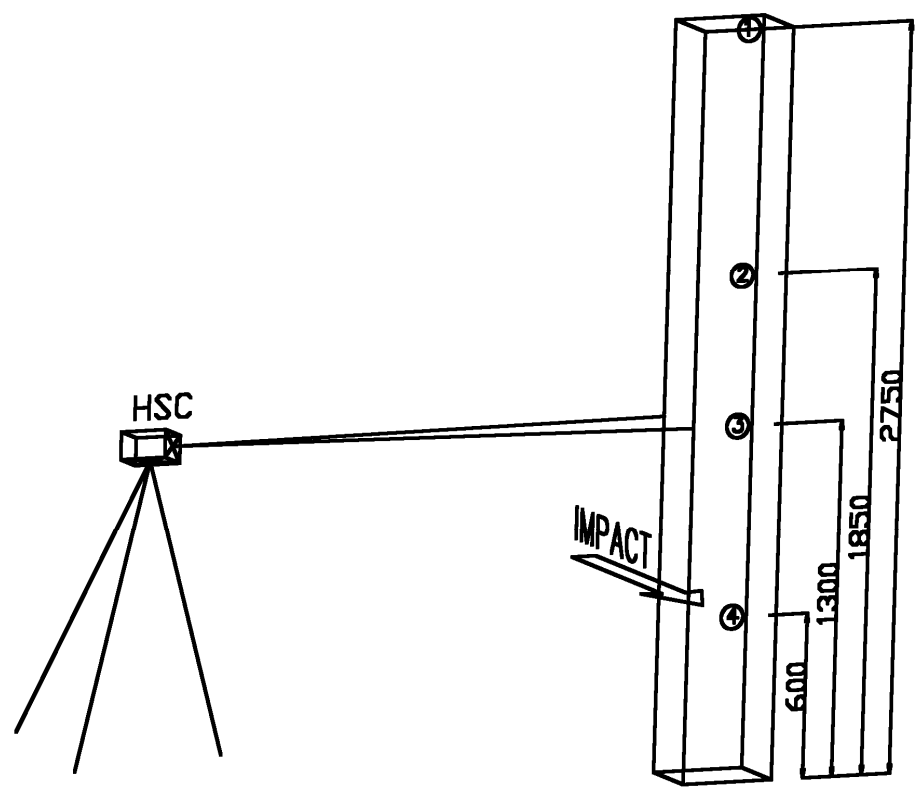

Figure 5: $\quad$ Location of points monitored $(\mathrm{mm})$. 
The velocity of the car in the moment of the impact was analyzed by means of a video camera with 30 frames per second, focusing at the end of the ramp. Several marks in the car allowed to measure the distance travelled between the last two frames before the impact and thus obtain the crash velocity.

Additional devices used are: Signal conditioner (482A22 PCB Piezotronics) with 4 channels, sensor interface for accelerometers (PCD-300A Kyowa) with 4 channels, sensor interface for linear displacement sensor and strain gauges (Spider8 HBM). Four points in the column were selected to be analyzed with these sensors. These points are located in the opposite face of the impact at $0.6 \mathrm{~m}$ (impact), $1.3 \mathrm{~m}$ (maximum displacement expected, $1.85 \mathrm{~m}$ and $2.75 \mathrm{~m}$ (upper part) high (figure 5).

\section{Experimental results and analysis}

\subsection{Final car condition}

One interesting result is the final condition of the car. The occurrence of plastic deformation in the car determines the importance of using of a real car in the experiments instead of a rigid projectile. For crash tests at high velocities large plastic deformations in the car are predictable but this is not so obvious for low velocity impacts.

All the five cars used in the experiments show noticeable plastic deformation (fig. 6). The maximum displacement of the frontal part in each car was measured (fig. 7) and the values are shown in table 2.

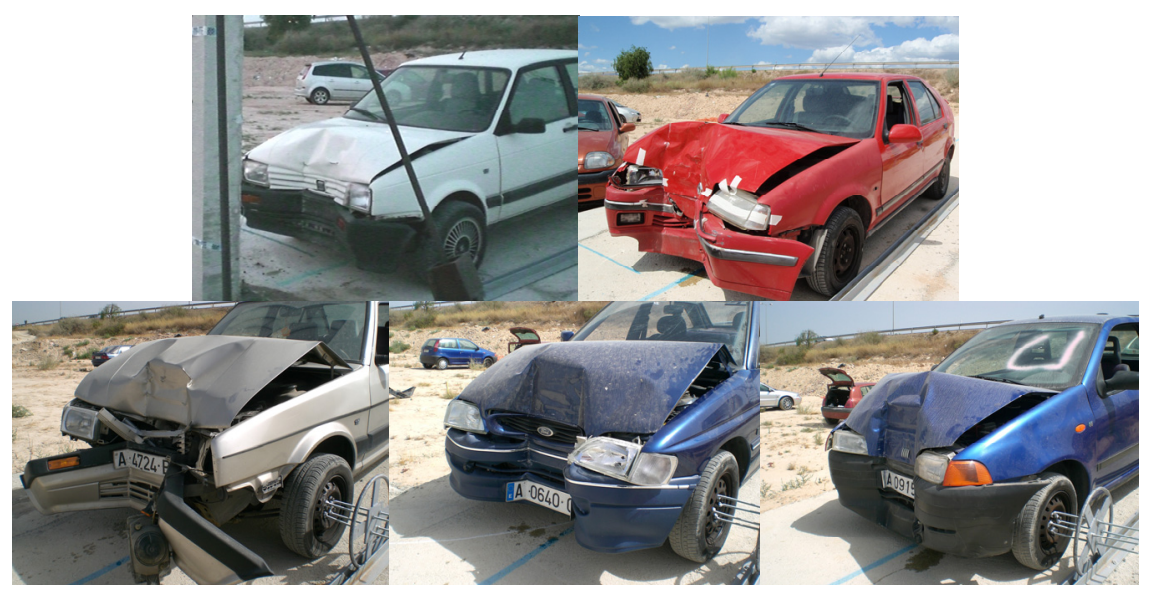

Figure 6: Final car condition after the experiments: Seat Ibiza, Renault 19 Chamade, Seat Málaga, Ford Escort, Fiat Punto. 


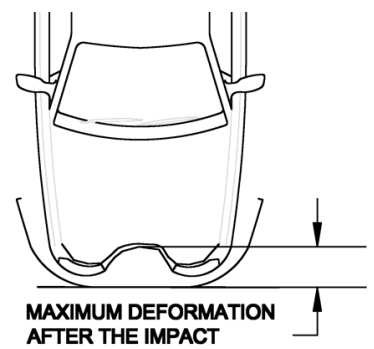

Figure 7: $\quad$ Measured distance in the car after the impact.

Table 2: $\quad$ Maximum plastic deformation in the car, according to fig. 7.

\begin{tabular}{ccc}
\hline Test & Vehicle & Maximum deformation $(\mathrm{mm})$ \\
\hline 1 & Seat Ibiza & 250 \\
\hline 2 & Renault 19 Chamade & 400 \\
\hline 3 & Seat Málaga & 300 \\
\hline 4 & Ford Escort & 240 \\
\hline 5 & Fiat Punto & 280 \\
\hline
\end{tabular}

\subsection{Column behaviour}

An example of registered acceleration is shown in fig. 8. The graph shows the data from the accelerometer located at point $3^{\text {rd }}$ in $4^{\text {th }}$ impact and its Fourier transform. For a more accurate visualization of the behaviour during the impact, an enlarged view of the first time period of the impact is shown in fig. 9. From this figure it is clear that there are two different behaviours. During the first 120 ms of recording, the signal is very irregular and no pattern can be observed. However, from time $120 \mathrm{~ms}$, a harmonic wave can be matched to the acceleration. The first part may correspond with the time during the car is pushing against the column while the second part corresponds to a free vibration of the column after car rebounds. This behaviour was observed in all the experiments and can be also seen with the HSC as we show in fig. 10. The duration of the irregular part coincides in both the accelerometer and the camera registers so the duration of loading in the column can be set in $120 \mathrm{~ms}$ approximately (figs. 9, 10).

The peak acceleration was obtained from each accelerometer, as it is shown in table 3 . It is noticeable that from $3^{\text {rd }}$ impact, the measured acceleration in point 1 ( $2.75 \mathrm{~m}$ from bottom) is higher than before. This can be due to the lost of load by the bars of the test frame. One must to take into account that the 3 latest experiments were done in the same day, 3 months after the loading of the bars and also 2 experiments after. In fact, during the change of the column done after the $5^{\text {th }}$ impact, the load in the bars could be checked and a value of $15.1 \mathrm{t}$ per bar was found, instead of $19.62 \mathrm{t}$ originally. 

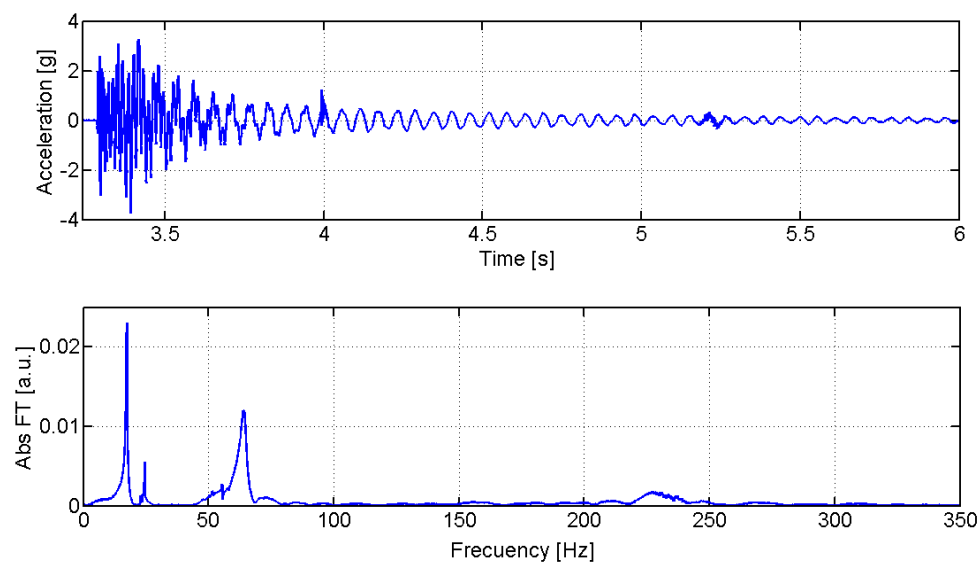

Figure 8: Recorded acceleration in the fourth experiment and Fourier transform.

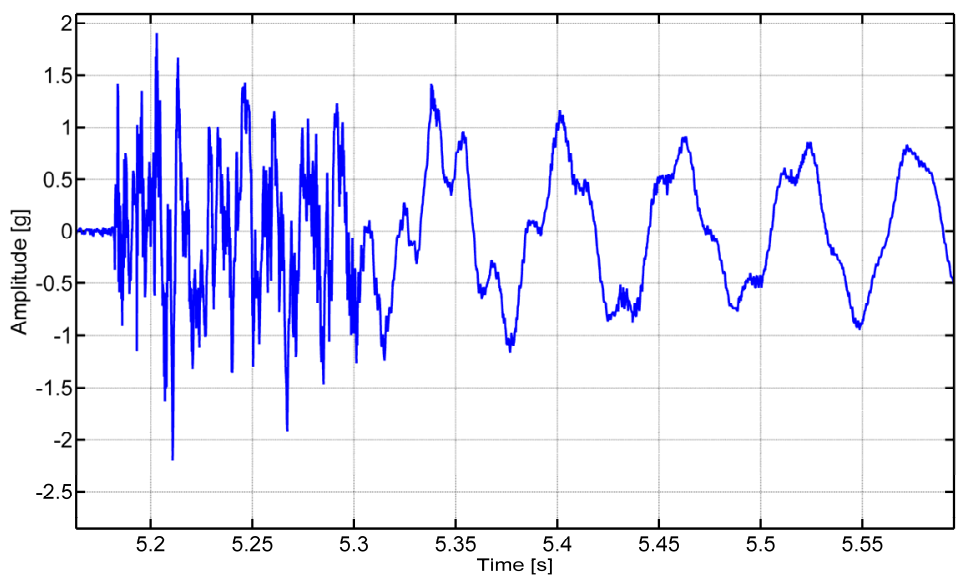

Figure 9: Detail of the recorded acceleration shown in fig. 8 - signal during the first time of the impact.

In fig. 8 one can see that the frequencies of the pillar are $17.3 \mathrm{~Hz}$ and $64 \mathrm{~Hz}$. A small peak at 17.4 can also be observed. These frequencies agree with the ones obtained from the HSC, as we show in fig 11. This feature was observed not only for this experiment but also for all of them (table 4). The camera show also very noisy data from $100 \mathrm{~Hz}$, but this is done to flickering in the image and no reliable data can be obtained in this region for the presented setup.

Although the data were also taken with LDS, the obtained frequencies do not always agree with those from the accelerometers. Thus, data from these devices were not considered and camera results were taken as real displacement data. We would also like to emphasize that the observed frequencies are decreasing with successive experiments, what agree with the fact that the bars lose load with the time and the crashes. 


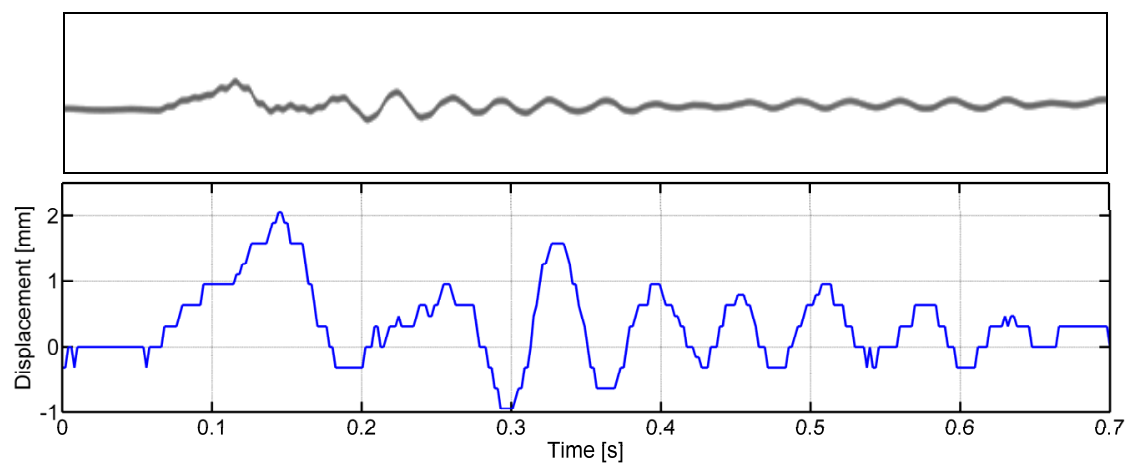

Figure 10: Results obtained from HSC in fourth experiment (top) and numerical reconstruction of this signal (bottom).

Table 3: $\quad$ Peak acceleration for each experiment in all the monitored points.

\begin{tabular}{cccccc}
\hline \multicolumn{7}{c}{ Peak acceleration } \\
\hline POINT & $1^{\text {st }}$ impact & $2^{\text {nd }}$ impact & $3^{\text {rd }}$ impact & $4^{\text {th }}$ impact & $5^{\text {th }}$ impact \\
\hline 1 & 3 & 1.8 & 5 & 4.3 & 4.4 \\
\hline 2 & 3.2 & 3.5 & 2.2 & 3.7 & 1.9 \\
\hline 3 & 4.5 & 4.5 & --- & --- & --- \\
\hline 4 & 3 & 3 & 2.8 & 3.8 & 2.9 \\
\hline
\end{tabular}

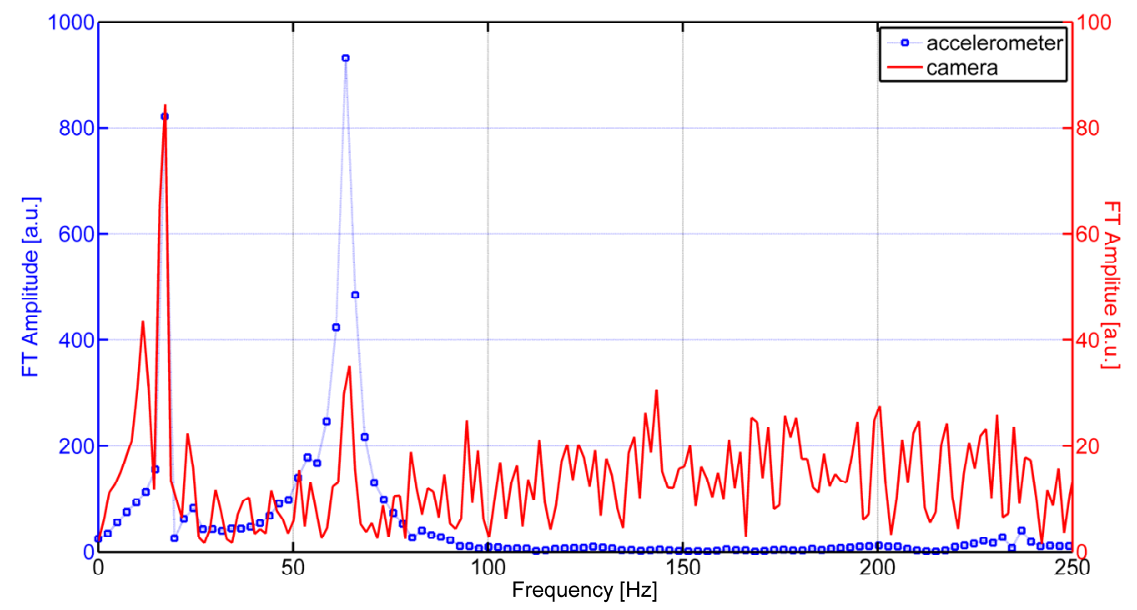

Figure 11: Fourier transform of LDS and HSC signal from the second impact. 
Table 4: $\quad$ Frequencies in each experiment and in each point.

\begin{tabular}{ccccccc}
\hline \multirow{2}{*}{ Point } & \multirow{2}{*}{ Sensor } & \multicolumn{5}{c}{ Frequency (Hz) } \\
\cline { 2 - 7 } & & $1^{\text {st }}$ imp. & $2^{\text {nd }}$ imp. & $3^{\text {rd }}$ imp. & $4^{\text {th }}$ imp. & $5^{\text {th }}$ imp. \\
\hline \multirow{2}{*}{1} & ACC & $19-69.7$ & $18.5-67.6$ & $17.2-63.6$ & $17.3-63.8$ & $17.5-64.4$ \\
\cline { 2 - 7 } & LDS & 19.04 & $18.5-44.2$ & 17.2 & 24.3 & 21.3 \\
\hline \multirow{2}{*}{2} & ACC & $19-69.8$ & $18.5-67.6$ & $17.5-64.8$ & $17.3-64$ & $17.5-64.4$ \\
\cline { 2 - 7 } & LDS & 19 & --- & 17.19 & 24.3 & 21.3 \\
\hline \multirow{3}{*}{3} & ACC & $19-69.8$ & $18.5-67.6$ & --- & --- & --- \\
\cline { 2 - 7 } & LDS & 19 & $44.2-56.9$ & 17.16 & 24.13 & 21.7 \\
\cline { 2 - 7 } & HSC & --- & $18-67$ & $17.3-64$ & $17.3-64$ & $17.5-64$ \\
\hline \multirow{2}{*}{4} & ACC & $19-70$ & $18.5-67.6$ & $17.4-64.4$ & 62.78 & $17.4-20.7$ \\
\cline { 2 - 7 } & LDS & --- & $44.2-56.9$ & --- & --- & --- \\
\hline
\end{tabular}

Table 5: Maximum displacement registered in the column in each impact at each point.

MAXIMUM REGISTERED DISPLACEMENT (mm)

\begin{tabular}{cccccc}
\hline POINT & $1^{\text {st }}$ impact & $2^{\text {nd }}$ impact & $3^{\text {rd }}$ impact & $4^{\text {th }}$ impact & $5^{\text {th }}$ impact \\
\hline $1($ LDS $)$ & 1.2 & 2.1 & 1.2 & 2.7 & 1.8 \\
\hline $2($ LDS $)$ & 2.7 & --- & 4.4 & 5.7 & 3.8 \\
\hline $3($ LDS $)$ & 1.2 & 3.8 & 1.8 & 2.6 & 1.7 \\
\hline $3($ HSC $)$ & 1.7 & 1.8 & 2.1 & 2 & 1.8 \\
\hline
\end{tabular}

The maximum displacement (table 5) also gives great differences between the values from LDS and those from HSC at point 3. The rest of values for LDS in other points have been included to show the lack of agreement between those values and data from the camera.

\section{Conclusions and ongoing work}

A new design was developed to perform real size car impact experiments against columns under compression. After some experiments, the movement of the higher part of the column is shown. Nevertheless, we believe that, in combination with a finite element model, the test frame can be useful to calibrate the concrete of the column in the model and, after that, to simulate different boundary conditions in the column.

After 5 experiments it is proved that, at a velocity of $20 \mathrm{~km} / \mathrm{h}$, the car has important plastic deformations and therefore, the use of real car in the study of low velocity impact is definitely necessary. In addition, the performed experiments show that, for an impact of $20 \mathrm{~km} / \mathrm{h}$ against a column, the duration of the loading is around $120 \mathrm{~ms}$.

The use of HSC in the determination of displacement during the impact was more reliable than the use of LDS. By means of HSC was obtained a maximum displacement of the column around $2 \mathrm{~mm}$ in all the experiments. 
Following this work, the next step will be the numerical modelization by means of finite element models to obtain a complete model that allows studying this problem without expensive experiments.

Another interesting study is the integration of the accelerometers signal to obtain displacement in the rest of measured points. To check this calculation, the values obtained from HSC can be used.

\section{References}

[1] "Eurocode 1: Actions on structures - Part 1-1: General actions - Densities, self-weight, imposed loads for buildings" Final Draft prEN 1991-1-1, European Committee for Standardization, 2001

[2] "Eurocode 1: Actions on structures - Part 1-7: General actions - Accidental actions" Final Project Team Draft (Stage 34), Draft prEN 1991-1-7, European Committee for Standardization, 2003

[3] "Eurocode 1: Actions on structures - Part 2-7: Accidental actions due to impact and explosions" ENV 1991-2-7, European Committee for Standardization, June 1998

[4] "Minimum Design Loads for Buildings and Other Structures", ASCE STANDARD, ASCE/SEI 7-05, American Society of Civil Engineers, 2006

[5] "2009 International Building Code", International Code Council, See http://www2.iccsafe.org/states/2009ICodes/Building/Building_Frameset.ht $\mathrm{ml}$ for further details. Accessed at 01/09/2009.

[6] “Actions on structures - Part 9: Accidental actions", DIN Deutsches Institut für Normung eV., August 2003

[7] Ferrer B., Ivorra S., Irles R., Low velocity vehicle impact: an outline of relevant codes, Proceedings-ICE: Structures \& Buildings, Submitted (2010)

[8] European New Car Assessment Programme (Euro NCAP). Frontal Impact Testing Protocol. Version 5.0. October 2009.

[9] Koh C. G., Liu Z. J., Quek S. T., Numerical and experimental studies of concrete damage under impact. Magazine of Concrete Research, 2001, 53, $N^{\circ}$ 6, December, 417-427

[10] Eibl J., Design of concrete structures to resist accidental impact. The Structural Engineer, Volume 65A, nº 1, January 1987

[11] Ferrer B., Espinosa J., Pérez J., Ivorra S., Mas D., Optical scanning for structural vibration measurement on a steel column, Submitted (2010) 